\title{
INFORME SOBRE LAS ACTIVIDADES LLEVADAS A CABO EN LA COMISIÓN NACIONAL DE LA ESPECIALIDAD EN PSICOLOGÍA CLÍNICA (CNEPC)
}

\author{
AMPARO BELLOCH ${ }^{1}$ y CONSUELO ESCUDERO ${ }^{2}$
}

Se detallan a continuación los principales aspectos que se han venido tratando en la Comisión Nacional de la Especialidad durante el último año.

1. Gestiones sobre la Ley de Cohesión y Calidad del Sistema Nacional de Salud, sobre la LOPS (anteproyecto de Ley de Ordenación de las Profesiones Sanitarias) y sobre el Estatuto Marco del personal estatutario de los Servicios de Salud. Desde mediados del año pasado y durante todo el presente se han enviado diversos escritos al Ministerio de Sanidad, al de Educación y a los grupos parlamentarios del Congreso, para proponer modificaciones en torno a las tres leyes. De hecho en la Ley de Cohesión se han recogido algunas de ellas y, por lo que conocemos, también en la LOPS. Las ultimas modificaciones de los grupos parlamentarios incluyen a la Psicología Clínica como profesión sanitaria en el artículo 6. De todas formas habrá que esperar el texto definitivo para confirmar su inclusión. Seguiremos al tanto de los cambios.

2. Desde la Comisión Nacional se ha propuesto realizar una jornada de trabajo para noviembre sobre la situación actual de la Especialidad. La organización estaría a cargo de AEPCP, la AEN y el COP.

\footnotetext{
1 Presidenta de AEPCP, Vocal de la CNEPC

2 Representante de AEPCP en la CNEPC
}

3. Homologación de títulos de especialista. Como se sabe, el $18 \mathrm{de}$ mayo de 2002 se publicó la Orden Ministerial 1107/2002 que regula las vías transitorias de acceso al titulo de Psicólogo Especialista en Psicología Clínica. El plazo de presentación de la documentación finalizó en febrero de 2003, comenzando en la primera quincena de octubre el proceso de evaluación de expedientes por parte de la Comisión Nacional.

En la última reunión habida el 18 de julio, se nos informó por parte del Ministerio de Educación, de que hasta la fecha se habían presentado alrededor de $\mathbf{1 0 . 5 0 0}$ expedientes, de los cuales la Comisión Nacional ha valorado e informado ya en torno a 1000. Se nos dijo también que el ritmo del proceso de valoración es el adecuado, dado el volumen de trabajo que representa, la complejidad de las vías transitorias y de las diversas situaciones de los profesionales que solicitan el título de especialista, todo ello unido además al hecho de que ninguno de los miembros de la Comisión se puede dedicar en exclusiva a esta tarea, que debe compatibilizar con el desempeño laboral de cada uno en su puesto de trabajo respectivo. Todo esto tiene como consecuencia inevitable la necesidad de contar con un tiempo mayor del que inicialmente se podía pensar: dicho en otros términos, debido al volumen de expedientes presentados, su complejidad, y la necesidad imperiosa de valorarlos con el 
máximo cuidado y dedicación, es totalmente imposible en la práctica resolverlos en el tiempo de 6 meses que marca la Orden Ministerial 1107/2002.

Para tranquilidad de todos los interesados, incluidos como es natural los miembros de la Comisión, la Administración (por medio de Dña. Marlis González, del Ministerio de Educación) nos informó de que el Art. 12 de la citada Orden, en el que se indica que las resoluciones serán comunicadas en el plazo de 6 meses a contar desde la fecha en que se hayan recibido las solicitudes, y que en caso de no haberse recibido respuesta por parte de la Administración, se puede entender desestimada la solicitud, tiene como finalidad proporcionar una garantía al ciudadano, en el sentido de que no quede desamparado a merced de la Administración. Sin embargo, es importante tener en cuenta que en la Ley de Procedimiento Administrativo (que es de rango superior a la Orden Ministerial), se dice expresamente que la Administración debe responder siempre. Desde este planteamiento, nos aseguró que la Administración responderá a todos los interesados con la resolución que corresponda (positiva o negativa), aun cuando se haya superado el plazo de 6 meses. Una vez recibida dicha respuesta, y en el caso de que no se adecuara a lo esperado por el solicitante, éste dispondrá a partir de esa notificación de los plazos legales correspondientes para interponer los recursos que estime oportunos y a los que las leyes le dan derecho.

Como todos sabemos, cualquiera tiene derecho, transcurridos 6 meses desde la remisión de su solicitud, de interponer los recursos contencioso-administrativos que estime oportunos. Ahora bien, es necesario saber que la interposición de un recurso antes de haber recibido la notificación expresa por parte del Ministerio sobre la resolución de su expediente, supone por ley la paralización del expediente en el Ministerio y en los trabajos de la Comisión, hasta que el Tribunal de Justicia ante el que se haya interpuesto el recurso dicte una resolución al respecto del mismo. El tiempo estimado para tal resolución puede ser (suele ser) mayor que el que hubiera supuesto el tiempo para la resolución del expediente de solicitud por el procedimiento normal, $y$, en todo caso, lo habitual es que el Juez dictamine su regreso a la Comisión Nacional para que exprese su opinión profesional sobre el mismo. Si este fuera el caso, hay que tener en cuenta además que por ley debería asignársele un nuevo orden de entrada o llegada, que como es lógico siempre sería posterior al inicial (tened en cuenta que los expedientes de solicitud se tramitan por riguroso orden de llegada al Ministerio). En definitiva, que sería muy improbable que el solicitante dispusiera de una respuesta antes por este procedimiento que por la vía normal. Todo ello sin olvidar que adoptar procedimientos de este tipo requiere una serie de gastos a asumir por el interesado (abogados, etc.).

Ante todo lo anterior, queremos expresaros con toda claridad nuestra opinión, que no es coincidente con la aparecida en otros órganos de expresión de los intereses de los profesionales de la psicología clínica (por ejemplo, en diversos boletines de delegaciones del COP).

a) El lapso de tiempo previsto para recibir contestación va a ser muy superior a los 6 meses inicialmente previstos en la Orden Ministerial, dado el enorme volumen de expedientes, su complejidad, la necesidad de valorarlos con el máximo respeto a los legítimos intereses del solicitante, y la disponibilidad limitada de tiempo por parte de los miembros de la Comisión, que a sus cometidos profesionales habituales, deben añadir este trabajo extra. Un 
cálculo realista nos sitúa en un tiempo no inferior a tres años para dar por finalizado el proceso.

b) La revisión de los expedientes de solicitud se realiza por riguroso orden de llegada al Ministerio de Educación. Una vez allí, se examina desde el punto de vista formal, la documentación aportada por el solicitante, para reclamarle en su caso los justificantes o documentos que falten. Una vez finalizado este proceso, que tiene como objeto garantizar la igualdad de oportunidades y derechos de todos los solicitantes, el expediente se remite a la Comisión Nacional para su examen y propuesta de resolución.

c) Está absolutamente garantizado que todos los que hayan solicitado el Título de Especialista en Psicología Clínica recibirán contestación por parte del Ministerio de Educación. Esta garantía obedece no solo a la voluntad y la palabra expresada por sus representantes ante todos los miembros de la Comisión Nacional de la Especialidad, sino además por el propio articulado de la Ley de Procedimiento Administrativo. A estos efectos, os recomendamos leer el Artículo 42 que expresamente dice: "La Administración está obligada a dictar resolución expresa en todos los procedimientos y a notificarla cualquiera que sea su forma de iniciación...". Os sugerimos leer los diferentes supuestos (entramos en varios de ellos) que justifican ampliar el plazo de respuesta inicialmente previsto en la Orden Ministerial.

d) Una vez recibida la respuesta o notificación correspondiente de for- ma oficial, y no antes en ningún caso, comienza a contar el tiempo fijado en el ordenamiento jurídico para interponer los recursos que se estimen convenientes, en el caso de que la resolución no se adecue a los legítimos intereses del solicitante.

e) En el caso de interponer recursos antes de recibir la notificación correspondiente, hay que asumir que el proceso de respuesta se va a prolongar más de lo que inicialmente le hubiera correspondido en función del orden de llegada del expediente al Ministerio de Educación.

f) Por lo tanto, no creemos que sea aconsejable en ningún caso interponer recurso alguno hasta haber recibido la notificación oficial en torno a la solicitud de homologación, en el caso de que ésta sea negativa y el solicitante no esté de acuerdo con ella.

Con todo lo expuesto, queremos trasmitiros a todos, además de la información pertinente y adecuada, una nota de tranquilidad respecto al proceso de homologación, que va a llevar más tiempo del que ingenuamente podíamos pensar en un inicio, dado el enorme volumen de trabajo que representa. Pero, al mismo tiempo, pensamos que ese tiempo es absolutamente necesario, si es que se quiere realizar con las máximas garantías de ecuanimidad y transparencia y que, al final, redundará en beneficio de todos y de la profesión.

En todo caso, estamos a vuestra disposición para cualquier duda que podamos resolver al respecto.

Valencia, Julio de 2003 